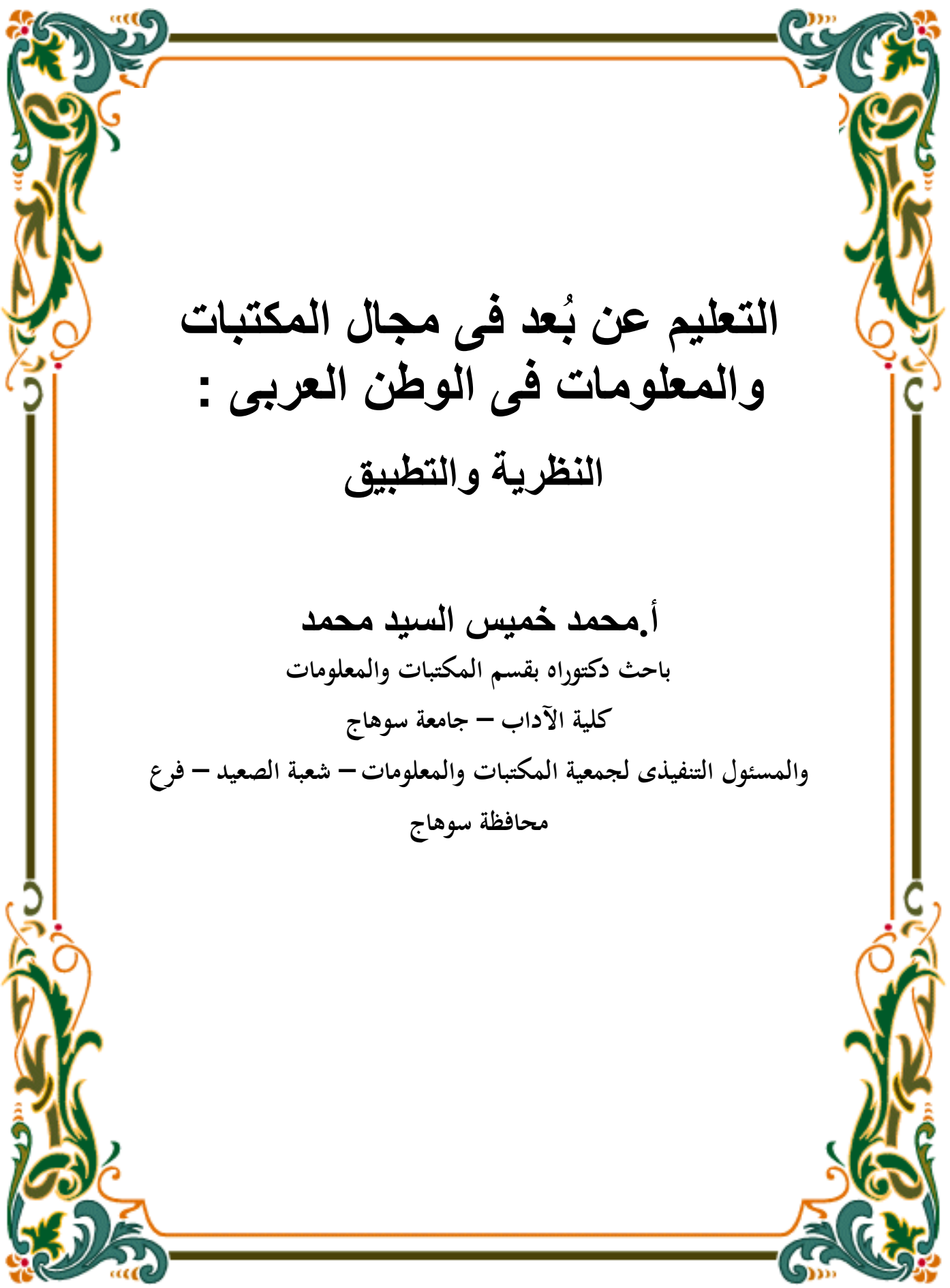




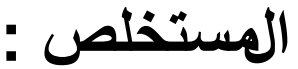

تُعد المؤسسات الأكاديمية الداعم الرئيس للعملية التعليمية، حيث يُعد استخدام

التقنيات الحديثة خصوصاً التعليم عن بُعد والتعليم الالكتروني القائم على نواتج

التكنولوجيا والتطور الرقمى المستمر هو من أكبر المهام التعليمية المنوطة

بالتخصص، فتخصص المكتبات و المعلومات من التخصصات التى تسعى لمو اكبة التطور التكنولوجى فى بيئة المكتبات فيُعد مجال المكتبات و المعلومات من التخصصات المهمة التى تخدم كل العلوم، حيث يتحول مجتمع التعليم من شكله التقليدى إلى استخدامه لوسائل التكنولوجيا و التفاعل معها، وذللك لما تتتجه هذه التقنيات من فرص أكثر مرونة وقدرة على تحقيق أفضل الأهداف و النتائج المرجوة من العملية التعليمية، حيث يساعد التعليم عن بُعد الطلاب على استخدام الوسائل و الوسائط التقنية و التكنولوجية و التعامل معها و الاستفادة منها، وفيما يلى نتناول التعليم عن بُعد فى مجال المكتبات و المعلومات فى الوطن العربى بين النظرية و التطبيق من خلال تناول مفهوم التعليم عن بُعد وأهميته ومبرر اته و أسباب استخدامه، وأبرز أنواع التكنولوجيا المستخدمة فى تقديم بر امج التعليم عن بُعد، إضافة إلى تناول أبرز نماذج التعليم عن بُعد فى الوطن العربى فى مجال المكتبات و المعلومات، و عرض أبرز المشكلات التى تو اجه تطبيقه فى مجال المكتبات و المعلومات بإتباع المنهج الوصفى باعتباره المنهج الأقرب لطبيعة الدر اسة، وصو لاً للنتائج ووضع التوصيات التى من شأنها يتم مو اجهة المشكلات التى تعوق تطبيق التعليم عن بُعد فى المجال. 


\section{الاستشهاد المرجعي:}

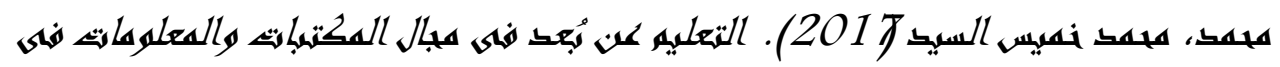

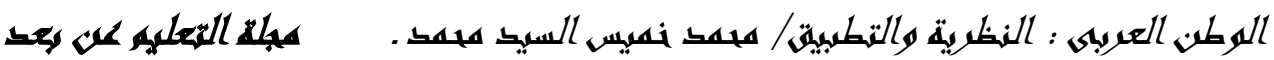

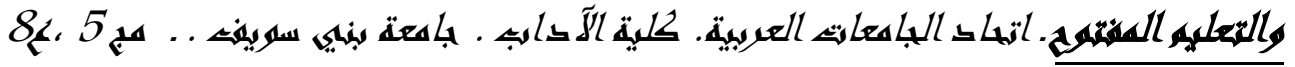

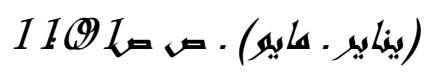


لقد أدى التطور التكنولوجى فى شتى المجالات إلى تطور وسائل الاتصال

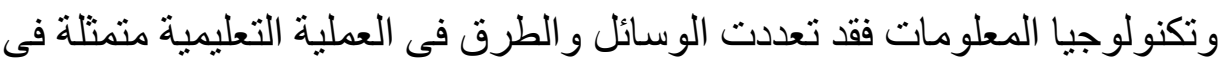
كافة نو احيها بداية من إنتاج المقرر الدر اسى حتى الانتهاء من اختبار الطالب، حيث أدت الاختراعات و الابتكار ات التكنولوجية إلى إحداث ثورة فى كافة المجالات وخصوصاً مجال الاتصال بدءاً من التلغر افات كوسيط لنقل المعلومات و انتهاءً بالأقمار الصناعية مما جعل العالم قرية صغيرة فى الاطلاع ومعرفة كافة الأحداث

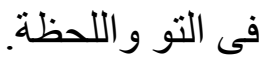

و أدى ذلك التطور إلى تطور المعلومات بسر عة هائلة مما أطلق عليها "الانفجار المعرفى أو المعلوماتى" مما يحتم بالضرورة العمل على التحكم فى هذا الانفجار من خلال استخدام وسائل التكنولوجيا فى حفظ وتخزين واسترجاع المعلومات من خلال الوسائل المختلفة.

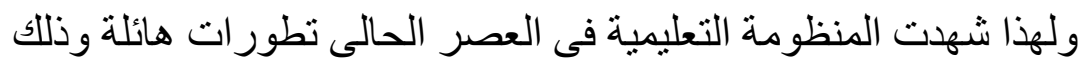
نتيجة لتوظيف تكنولوجيا المعلومات و الاتصالات و التعليم الإلكتروني، وقد أثر ذلك فى جميع عناصر المنظومة التعليمية بما تتضمنه من مقررات واستر اتيجيات و أساليب للتعليم و التعلم وطرق التنريب، وقد أدى ذلك إلى زيادة فاعلية وكفاءة

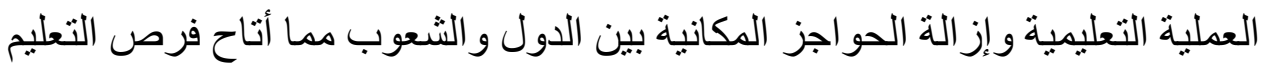
أمام الجميع فى أى وقت و أى مكان.(') ونتيجة لهذا التطور برزت الحاجة إلى الاستفادة الكاملة من مخرجات

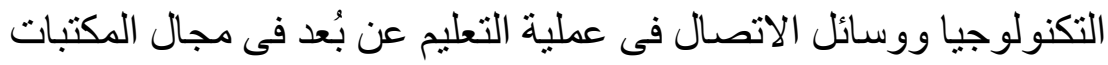
و المعلومات والتحول من التعليم من الثكل التقليدى إلى الثكل الرقمى الالكترونى. ولذلك جاءت الدراسة لتتناول التعليم عن بُعد فى الوطن العربية بين النظرية

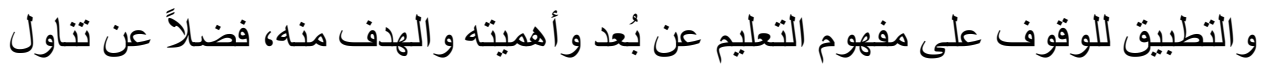


النماذج للدول العربية لنطبيق برامج التعليم عن بُعد فى المجال، موضحاً أبرز المشكلات التى تو اجه تطبيق التعليم عن بُعد فى الوطن العربى.

\section{مشكلة الدراسة:}

تتمثل مشكلة الدر اسة فى التحديات التى تو اجه التعليم العالى بشكل عام مما يؤكد ضرورة توفير فرص كافية للاستثمار فى توظيف تكنولوجيا المعلومات و الاستفادة منها فى مجال المكتبات والمعلومات فى الوطن العربى، إضافة إلى عدم مو اكبة التطور الهائل فى المجال وأن بعض المقررات قديشوبها من الملل فى أسلوب العرض، بالإضافة إلى عدم وجود آليات للتحديث المستمر، ووجود قصور فى أسلوب عرض المعلومات للطلاب مما لا يحقق الإلمام الجوهرى بمضمون المعلومة، فضلاً عن محدودية المر افق والتجهيزات غير الكافية فى العملية التعليمية التى يعانى منها الطلاب والباحثين فى مجال المكتبات.

\section{أهداف الاراسة:}

تهرف الدر اسة إلى تحقيق هدف عام وهو " التعليم عن بُعد فى مجال المكتبات و المعلومات فى الوطن العربى" ويخرج من هذا الهدف مجمو عة أهداف فرعية هى:1 ـ التعرف على مفهوم التعليم عن بُعد مفهومها، و أهميته ، و أهدافه. r -توضيح مبررات وأسباب تبنى التعليم عن بُعد فى مجال المكتبات

$$
\text { و المعلومات فى الوطن العربى. }
$$

r ـ التعرف على أبرز النماذج فى تطبيق التعليم عن بُعد فى مجال المكتبات

$$
\text { و المعلومات فى الوطن العربى. }
$$

ـ ـ توضيح المشكلات و العقبات التى تواجه تطبيق التعليم عن بُعد فى مجال المكتبات و المعلومات . 
تتمثل أهمية الدر اسة فى أهمية الموضوع نفسه، حيث يُعد التعليم عن بُعد بالنسبة للاول النامية أسلوباً فعالاً لما يقدمه من فرص تساعدها على تحقيق أهدافها التعليمية على مستوى النظام التعليمى ككل، كذلك يؤدى التعليم عن بُعد إلى تتمية مهار ات الطلاب و المتخصصين فى مجال المكتبات و المعلومات من أجل الحفاظ على قاعدة بحثية قادرة على المنافسة وتحسين نشر المعرفة وتقديم الخدمات على الوجه

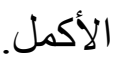

\section{: مiهج الدر اسة}

لإعداد الدر اسة وجمع البيانات حولها والتعرف على مختلف جو انبها و أبعادها اتبع الباحث المنهج الوصفى الذى يقوم على وصف الواقع وجمع البيانات وتفسير ها

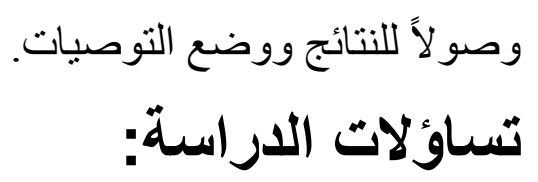

تجيب الدر اسة على عدة تساؤ لات تتمثل فى أهداف الدر اسة وهى كالتالى:ا ـ ما مفهوم التعليم عن بُعد مفهومه، و أهميته ، و أهدافه؟.

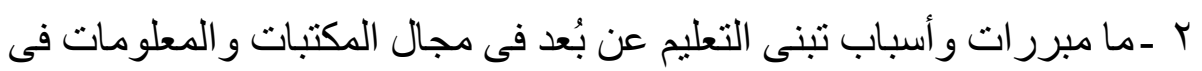

$$
\text { الوطن العربى؟ مبرو }
$$

r ـ ما أبرز النماذج فى تطبيق التعليم عن بُعد فى مجال المكتبات و المعلومات

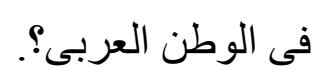

ـ ـ ـما المشكلات و العقبات التى تو اجه تطبيق التعليم عن بُعد فى مجال المكتبات

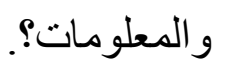


• نظر اً للتطور التكنولوجى المستمر الذى أثر فى كافة جوانب العلوم و التخصصات مما أثر فى التعليم بشكل كبير فإننا نقف على توضيح مفهوم التعليم عن بُعد و أهميته و أهدافه. • مفهوم التعليم عن بُعد:

هنالك عدة مفاهيم وتعريفات لمصطلح التعليم عن بُعد حيث ظهرت عدة مسميات تعرف تارة بالتعليم المفتوح أو التعليم الأفتر اضى وتارة بالتعليم المنزلى و أخرى بالتعليم على الخط المباثر أو التعليم الإلكترونى إلى غير ذلك من المسميات و الأوصاف، وإن دل ذلك فهو يدل على أن التطور الكبير للتكنولوجيا الحديثة للمعلومات والاتصال التى قلبت رأساً على عقب كل الممارسات فى حياة الإنسان

ولم يستثنى من ذلك الميدان التربوى و التعليمى الذى يثهد تطوراً كبيراً. (r)

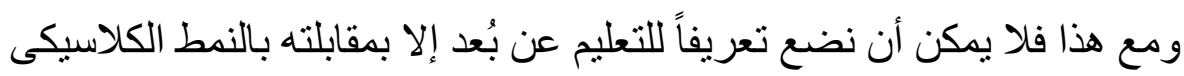
للتعليم أو ما يسمى بالتعليم التقليدى بين الجدران، وبهذا يُعرف التعليم بُعد بأنه" نظام

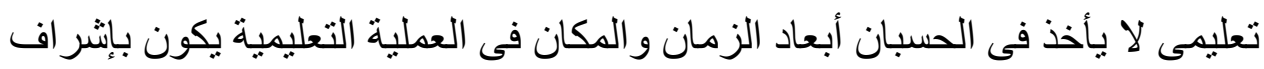
وتخطيط تربوى محكم، أى أن المتعلمين ليسو ا مجبرين أن يتو اجدون فى المكان نفسه و الوقت نفسه الذى يوجد فيه المعلمون وقد تعزز هذا المفهوم بعد ظهور

$$
\text { الشبكات وتكنولوجيا المعلومات"(") }
$$

كما يعرف التعليم عن بُعد بأنه " أحد النماذج التى تسهم بمساعدة الفرد فى الحصول على المعرفة و العلم و التدريس الذى يحتاجه وهو يعمل على توفير فرص التعليم

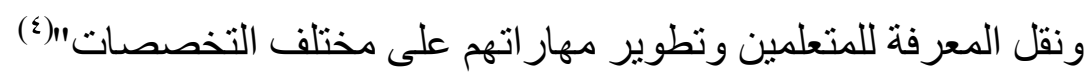
وتعرفه اليونسكو بأنه " الاستخدام المنتظم للوسائط المطبو عة و غير هاو هذه الوسائط يجب أن تكون معده إعداداً جيداً من أجل تيسير الاتصال بين المتعلمين

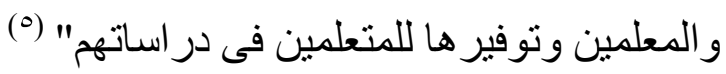


ويخرج الباحث بتعريف إجرائي للتعليم عن بُعد بأنه " أسلوب منظم لتطبيق وسائل الاتصال و التكنولوجيا فى عملية تعليمية هدفها الارتقاء بمستوى الطالب وتوصيل المعلومات وتخطى حدود المكان و الزمان لتحسين مستوى وجودة التعليم". ومن خلال تللك التعريفات يمكننا بالخروج بعدة خصائص للتعليم عن بُعد تتمثل فى (7) النقاط التالية:ا ـ الإمداد بتفاعل من حين إلى حين مع أعضاء هيئة التدريس. r - إمداد الطالب بدر اسة مستقلة وفردية. r - يتم تلقيه من خلال مقرر ات داخل وخار ج الحرم الجامعى. ع - يعتمد على احتباجات الطالب الفعلية.

إضافة إلى ذلك هنالك عدة خصائص للتعليم عن بُعد لعل أهمها الأتى:- (v) 1 ـ القدرة على تلبية الاحتياجات الاجتماعية و الوظيفية و المهنية للمستحقين به لما يتمتع به من مرونة وحداثة وتوفير البدائل من جهة وارتباطاته بحاجات سوق العمل للعمالة. r ـ انتفاع هذا النمط من التعليم بالثورة التكنولوجية وثورة الاتصالات و اعتماده الرئيس على الوسائط التكنولوجية الحديثة ووسائل الاتصال المعاصرة. r ـ أن التعليم عن بُعد يعتمد على الطريقة النظامية المنهجية فى تحديد البر امج

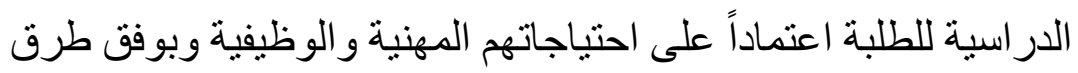
و أساليب وتقنيات فى التعليم تتصف بالمرونة. •أهمية التعليم عن بُعد:

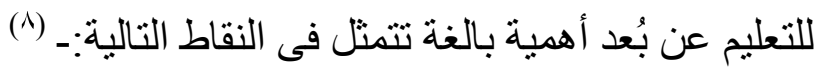
ا ـ ـوفير التعليم فى كل زمان ومكان. r -رفع الجدوى الاقتصادية للعملية التربوية بخفض تكاليفها. r ـ تلبية احتياجات المتعلمين و الاستجابة للفروق الفردية بينهم. 
ع - يساعد التعليم عن بُعد فى ضبط إدارة المعلومات فى ظل الانفجار المعرفى

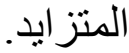

ه ـكما يمتاز التعليم عن بُعد بإثغال المتعلمين يو اكبون الطفرة السريعة فى مجالات التعليم و المعلومات و الاتصالات مما يساعدهم على الالتحاق

$$
\text { بالدر اسات العليا و الجامعية. }
$$

\section{• أهداف التعليم عن بُعد:}

تتو افق أهداف التعليم عن بُعد مع أهداف التعليم التقليدى إلا أن هناك أهدافاً نو عية

خاصة تتميز بها الجامعات المفتوحة التى تعتمد على التعليم عن بُعد ولعل أبرز ها

(9)

ا ـ توفير فرص التعليم والتدريب و النمو المهنى المستمر للطلاب و الباحثين فى

مجال المكتبات و المعلومات.

r ـ تحقيق مبدأ ديمقر اطية التعلم ودعم تكافؤ الفرص التعليمية وتطبيقاتها فى أنواع التعليم ومسئولياته المختلفة بما يتبعه للمحرومين من التعليم من فرص الانخر اط فيه من دون تمبيز فيما بينهم لأسباب تتعلق بمكانتهم الاجتماعية أو الاقتصادية أو بسبب الجنس أو اللون أو الدين.

ب ـ الإسهام فى تطوير نو عية التعليم باستثمار الوسائط التقنية الحديثة المتنوعة التى أثتبت فعالية المتعلم عوضاً عن التلقين السلبى السائد. ع - بناء شخصية ايجابية للطلاب و الباحثين فى المجال قادرة على العطاء وحل المشكلات وتحقيق التنمية الذاتية.

ه ـ توفير أساليب ووسائل تعليمية مغايرة لتلك الموجودة فى التعليم التقليدى. 7 ـ توفير التعاون العلمى والبحث بين مؤسسات التعليم العلمى. 
ثانياً: مبررات وأسباب استخدام التعليم عن بُعد فى مجال

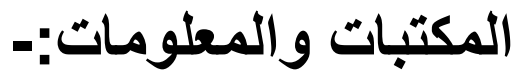

لعل من أبرز مبررات استخدام التعليم عن بُعد فى مجال المكتبات هو أن أمناء المكتبات يعتمدون ولحد كبير على مدى تألفهم مع تعدد أنماط مو ارد المعلومات المتاحة فى أشكال إلكترونية و استخدام هذه الموارد بطريقة تحقق عائد من فاعلية التكلفة، كذلك الوصول الأفضل للمجتمع الذى تنشده، و الإمداد بتعليم أفضل مما يقدمه التعليم التقليدى داخل أسوار الجامعة، إضافة إلى التغلب على المشاكل و العو ائق التقليدية لعملية التعليم ؛ كما يعمل التعليم عن بُعد على حل مشكلة نقص فى أعداد الخريجين من أقسام المكتبات الأكاديمية لتلبية احتياجات سوق العمل وحركة التنمية الثاملة التى تشهدها مصر وباقى الدول فى الوطن العربى.(·") كما أن هناك جملة من المبررات تكاد تكون عالمية تتسبب عادة فى أنظمة التعليم عن بُعد ومنها التغلب على البعد و الاستجابة لحاجات اجتماعية وتربوية، ولعل أبرز مبررات الأخذ بنظام التعليم عن بُعد ينحصر فى الأتى:- (') ا ـ عدم التو ازن فى التوزيع الجغر افى للمؤسسات التعليمية فهناك مناطق ودول تتوفر فيها مؤسسات جامعية بينما تفتقر بعض المناطق و الدول لمؤسسات التعليم العالى، فالمناطق التى تفتقر لهذه المؤسسات يجد أبناؤها صعوبة فى مو اصلة تعليمهم فالتعليم عن بُعد يأتى لتحقيق آمال وطموحات أبناء هذه المناطق. r ـثورة وغزارة المعلومات التى يشهدها القرن، فلا شك من أن ملامح النصف الثانى من القرن العشرين الماضى شهـ تدفق فى المعلومات وصعوبة متابعة تدفقها بالنسبة لأى مؤسسة تعليمية ويعتمد هذا التدفق على التطور

$$
\text { التكنولوجى السريع. }
$$


ب ـ الزيادة الكبيرة فى أعداد المتعلمين الراغيجن فى التعلم مما يجعل المؤسسات التعليمية عاجزة عن توفير التعليم لتلك الأعداد المتز ايدة فى ظل الإمكانات المحدودة للمؤسسة الحالية أمام عدد كبير من المتعلمين.

ـ ـ إخفاء روح المسئولية عن التعليم، وهذه الطريقة تترك للار اسة نصيباً وافراً من المسئولية فى تنظيم محيط تربوى بينما يحتل الدارس مسئولية تعليمه الذاتى.

\section{ثالثاً: أبرز أنواع التثنولوجيا المستخدمة فى التعليم عن بُعد فَى مبال المكثبات:-}

هنالك عدة أنواع من وسائل التكنولوجيا المستخدمـــــــة فى بر امـج التعليم عن بُعد تتمثل فى الأتى:- (r) - (i) 1 ـ المواد السمعية: فى هذا النوع تعتمد فى ايصال التعليم عن بُعد على تقنية الحدث وهناك العديد من الخيار ات فى تقنية الصوت فقد تلجأ مؤسسات التعليم عن بُعد إلى استخدام أشرطة الكاسيت أو تسجيل المادة العلمية على شريط و إرساله إلى الدارسين ومن ثم يستمع إلى شرح المادة العلمية من خلاله ويتعلمها ويستو عبها؛ حيث تتميز هذه الطريقة بسهولة الإعداد باستخدام مسجلات الأشرطة العادية فى أن تسجيلها سهل وقليل التكاليف. r ـ أشرطة الفيديو: تستخدم أشرطة الفيديو الصوت و الصورة معاً وتستخدم فى بـ تسجيل المحاضر ات و إعادة بثها ويمكن إعطاء كل دارس مجمو عة من الأشرطة تحتوى المادة الدارسية، حيث تتميز هذه الطريقة بشأنها تساعد على شرح المادة العلمية بطريقة فعالة فمن خلالها يمكن عرض المعامل و العروض المرئية وتقرب المادة إلى أذهان الدارسين. 
r ـ الفيليو تكس: يقدم الفيديو تكس خدمات تبادلية وباتجاهين ومتصل بخط

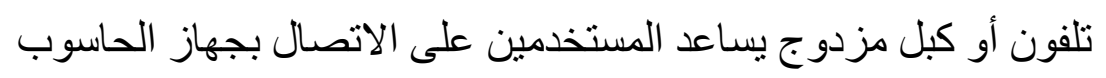

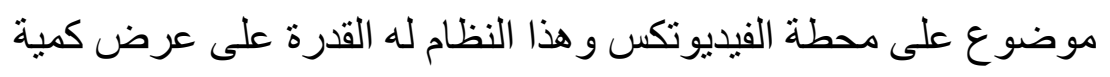
كبيرة من النصوص و الصور على شانشة التلفزيون أن يتكلم مع مصمدي

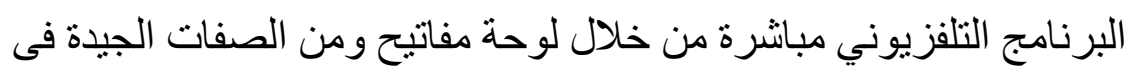
الفيديو تكس انه يمكن الدارسين من الوصول إلى كميات هائلة من البيانات و المعلومات المتخصصة.

ع ـ شبكة الانترنت: يُعد الانترنت عبارة عن شبكة حاسوبية عملاقة عالمية تتكون من عدة شبكات تصل إلى مستخدمى الحاسوب في أنحاء العالم ويتر اوح عدد الثبكات المدرجة تحت شبكة الانترنت بملايين الثبكات

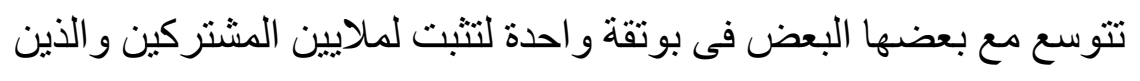

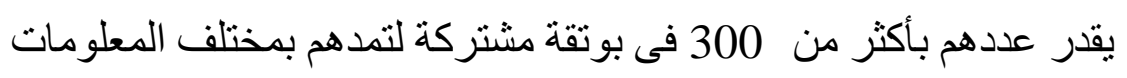
المطلوبة.

\section{رابعاً: المشكلات التى ثواجه التعليم عن بُعد فَى مجال المكتبات والمعلومات فى الوطن العربى:-} رغم ما تسعى له الدول العربية من القيام ببرامج التعليم عن بُعد إلا أن هنالك العديد

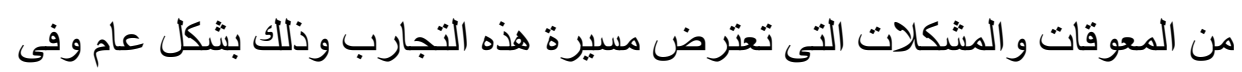

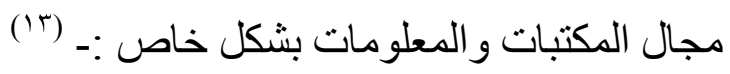

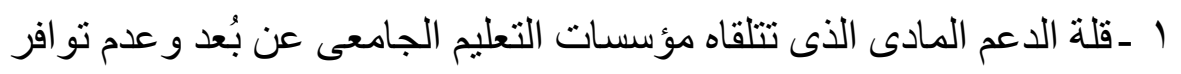

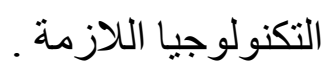

r ـ منافسة الجامعات التقليدية التى تتمتع بشهرة كبيرة مقارنة بهذه المؤسسات. 
r ـ معاناة التعليم الجامعى عن بُعد من انخفاض المكانة الاجتماعية حيث يُعد

تعليماً من الدرجة الثانية يرتديه فقط من لم يقدر اجتماعياً أو مادياً على لئ امتلاك أشكال التعليم التقليدى.

ـ ـ غياب وضوح الرؤية الصحيحة للتحليم عن بُعد لدى قطاع مؤثر من الناس المسئولين مما يؤدى إلى النظر إليه كتعليم من الدرجة الثانية. ـ ـ تفتقد معظم الجامعات العربية إلى الر ابطة القومية مع المؤسسات و الثركات الصناعية والتجارية و الخدمية الكبرى و هذه الر ابطة من العناصر الأساسية

لإنجاح التعليم التخصصى المهنى المتقدم لما لها من أثر فى دعم التنمية الاجتماعية إلا أن الوسائل التعليمية فى مجال التخصص غير منوفرة بالقدر

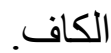
1 ـ أجهزة العرض غير صالحة للعمل فى معظم المجالات بالإضافة لعدم توفير الخدمات اللازمة لإنتاج المو اد التعليمية.

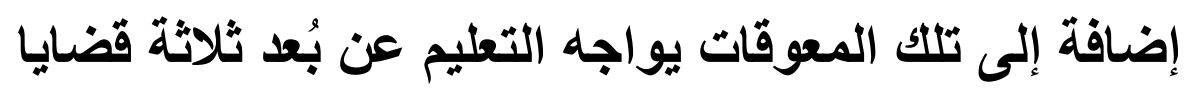
رئيسية تتمثل فى النقاط التالية:-

ا ـ اللغة: فاللغة الأساسية لنبكة الانترنت ومنتجات الملتميديا وبر امج الكمبيوتر هى اللغة الانجليزية بغض النظر عن كون الكورس نفسه مصمماً باللغة الانجليزية، ولذلك فإن طالب التعليم عن بُعد الذى يدرس من خلال أنظمة ووسائل التعليم الافتر اضى يتحتم عليه أن يكون ملماً باللغة الانجليزية ويجيدها إجادة تامة للأغر اض الأكاديمية، حيث أن عدم الإلمام باللغة الانجليزية يقف حائلاً أمام أعداد كبيرة من الذين لا يودون التعليم عبر الثبكات. 
r ـ محتوى المادة العلمية: ويُعد محتوى المادة العلمية من المشكلات التى

تو اجه التعليم عن بُعد فى مجال المكتبات و المعلومات بشكل عام فهى

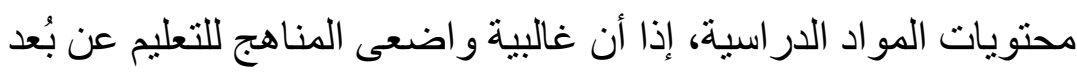

ومصممى البر امج قد يأتون من بيئة واحدة كالبيئة الغربية مثناً، وقد يتسبب

هذا الوضع فى خلق نوع من المشكلات التى تنتج نتيجة لاختلاف البيئات

والثقافات فقد تستخدم بعض المرئيات أو بعض العبار ات فى مقررات در اسية فى الأدب أو تدرس أو ثرصد بعض الثقافات.

r ـ أسلوب التدريس: هى مشكلة تتعلق بالكيفية التى تدار بها عمليتا التدريس

و التعليم واستيعابها فى منظومة الاتصال عبر الحاسب عندما لا يتيسر الاجتماع بين الطلبة والأساتذة وجهاً لوجه إلا نادراً وقد لا يجتمعون أصلاً. خامساً: نماذج من تجارب بعض الأول المطبقة للتعطيم عن بُعد فى مجال المكتبات والمعلومات فى الوطن

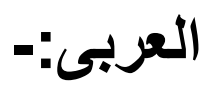

وفيما يخص التعليم عن بُعد المتخصص فى ميدان المكتبات و المعلومات بصفة عامة فعلى الرغم من المعلومات القليلة المتوفرة لدينا، فإن الو لايات المتحدة الأمريكية وكندا تحتلان الصدارة فى هذا المضمار و إن كانت القو انين و التشريعات التى تحكم التعليم و التأهيل فى هذا الميدان تختلف من و لاية إلى و لاية أخرى؛ بينما التعليم عن بُعد فى أوروبا وإن كان عرف أشوطاً كبيرة إلا انه فى مجال المكتبات والتوثيق هو

فى بداياته الأولى وإن كانت المعلومات الدقيقة غير منو افرة. أما فى العالم العربى فإن غياب الدر اسات التجريبية والمنشور ات العربية المتخصصة فى الميدان لخير دليل على قلته فى مؤسسات التعليم و التكوين العربية المتخصصة باستثناء بعض التجارب القليلة ومن تلك التجارب التالى :- (؛ (") 
1 ـ تجربة المعهد العالى للتوثيق بتونس الذّى نظم تكوينات للمكتبيين و الوثائقين عن بُعد للموسم الدر اسى 2003/2002م باستعمال أرضية اكو لاد للتعليم التعاونى عن بُعد إضافة إلى التجربة الأولية لمركز البحث فى الإعلام العلمى و التقنى بالجز ائر فى إعداد متخصصين فى المعلومات و التوثيق و الوقوف على الجوانب التنظيمية التقنية والفنية والسيناريو التعليمى المتبع ومدى مطابقته للأسس و المناهج النظرية التى يقوم عليها التعليم عن بُعد. كما يعرض د. محسن العرينى فى كتابة التعليم عن بعد للمكتبات و المعلومات بعض النماذج التى طبقت التعليم عن بعد فى الوطن العربى ومنها:- (10) r - تجربة جامعة الملك عبد العزيز للتعليم عن بُعد ، وذللك نتيجة لعدم اختلاط الجنسين فى المر احل بالمملكة العربية السعودية تستخدم الجامعات السعودية الدوائر التلفزيونية المغلقة فى التلقين لقسم الطالبات، حيث تدرس الجامعات بعض مقرر اتها بإحدى طرق التعليم عن بُعد وهى الدوائر التلفزيونية . ب ـقدم د. سعد الهجرسى فى يناير 1985م سلسلة متصلة من الحلقات الإذاعية عن المكتبات وبنوك المعلومات فى حلقات عرفت باسم حديث السهرة وكان عنو انها الإذاعى "المكتبات وبنوك المعلومات فى حديث السهرة " وتناولت الحلقات موضو عات المكتبات وبنوك المعلومات ، و الحاسب الآلى ، الضبط البيليوجر افى، و قضايا التعليم و المعلومات. ع -فى عام 1968م عقدت ندوة بمدينة المنامة عن التعليم العالى عن بُعد وركزت هذه الندوة على مشروع الجامعة المفتوحة للدول الأعضاء بمكتب التربية العربى لدول الخليج. 


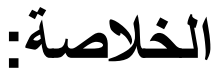

أن تكنولوجيا المعلومات ووسائل الاتصال تعمل على الارتقاء بالمستوي التعليمي و النهوض بالعملية التعليمية إذا تم استخدامها وتطبيقها بشكل علمى فعال وفق قو اعد وأسلوب منهجى منظم، فهو عملية نظامية الهدف منها وضع حلولاً للعقبات و المشكلات لتى تو اجه التعليم التقليدى، وقد يحتم ذلك ضرورة السعى من قبل الدول العربية لتبنى مثل هذه التجارب و العملى على الاستفادة من التكنولوجيا ومخرجاتها فى مجال التعليم.

\section{نتائج الدراسة:}

1 ـ ضعف فى تبنى الدول العربية لبر امج التعليم عن بُعد وتطبيقها فى مجال المكتبات و المعلومات، فأنظمة التعليم التقليدية أصبحت عاجزة عن عن تحقيق طموحاتها. r ـ أن التعليم عن بُعد يشكل خطوة كبيرة نحو التقدم والرقى و التنمية البشرية

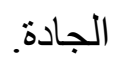

r ـ يعتمد مستقبل أخصائي المكتبات و المعلومات على مدى استفادته من التكنولوجيا ووسائل الاتصال فى القيام بجميع المهام و الوظائف. ع ـ لعل السبب فى نجاح برامج التعليم عن بُعد فى المكتبات و علم المعلومات إلى التعاون بين كافة الجهات القائمة عليه من أساتذة متخصصين و أخصائي

وسائط تعليمية ومديرى المكتبات ومصممى النظم و الأجهزة.

\section{ثوصياث الدراسة:}

I ـ إعادة النظر فى التجارب العربية و السعى على تطوير ها و الاستفادة من تكنولوجيا المعلومات ووسائل الاتصال فى العملية التعليمية. 
r - أن تقوم المكتبات ومر اكز المعلومات فى ظل البيئة الرقمية والتكنولوجية على بث الدور ات التدريبية من خلال استخدام شبكات الانترنت. r ـ ضرورة إيجاد أنظمة وأساليب ووسائل حديثة لتقديمها و تتمثل هذه الوسائل فى تكنولوجيا المعلومات و الاتصال التى تسهم بصورة فعالة فى التخلب على العديد من المشكلات. ع ـ أن تتولى أقسام المكتبات بالجامعات المصرية و العربية و السعى جاهدةً على له تحقيق التوقعات المستقبلية والاستفادة من التكنولوجيا فى تقديم مقررات التعليم عن بُعد، و العمل على الاستفادة من التجارب الأجنبية و السعى لإعداد مقرر للتعليم عن بُعد. 


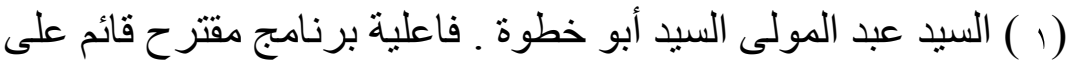

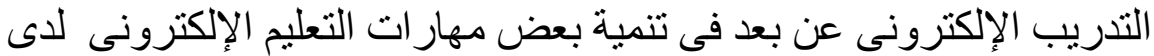

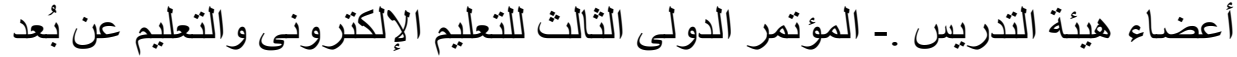

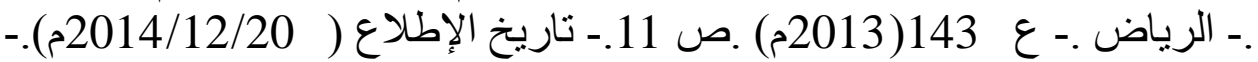
متاح على:http://www.eli.elc.edu.sa/2013/sites/defcault /rp42.pdf

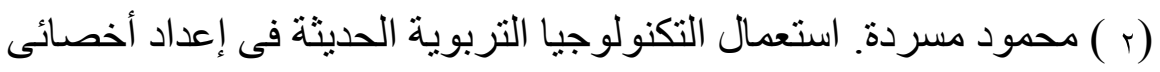

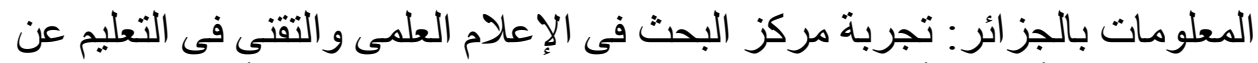

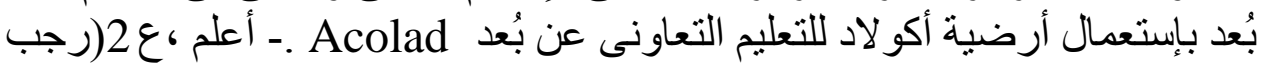

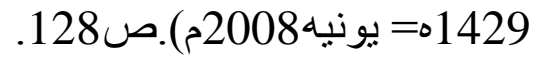

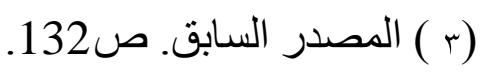

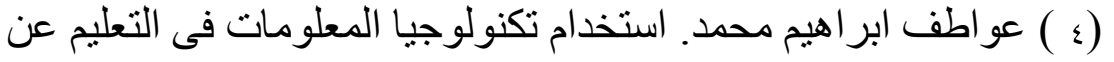

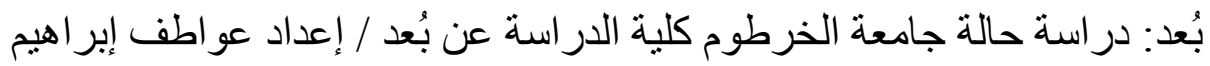

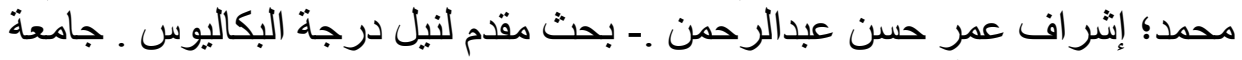

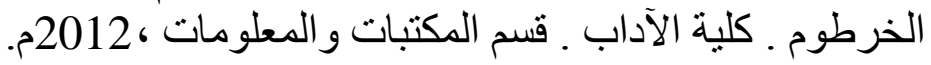

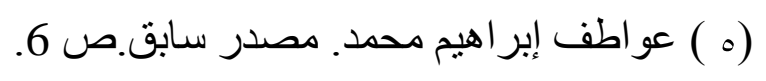

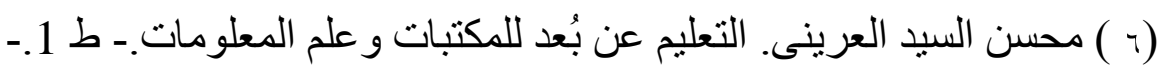

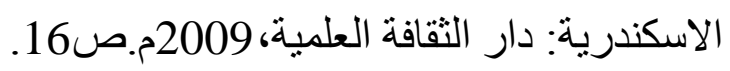

$$
\text { ( ) عو اطف ابر اهيم محمد. المصدر السابق .صوبة. }
$$

(ه ) على بن شرف الموسوى ـ التدريب الإلكترونى وتطبيقاته فى تطوير

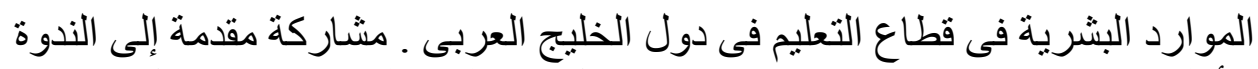

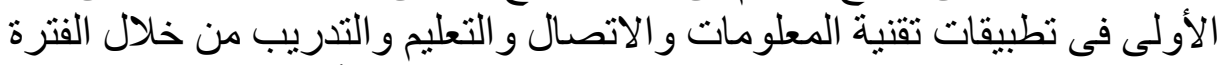

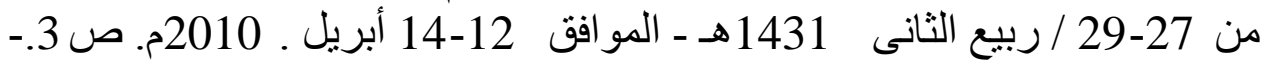

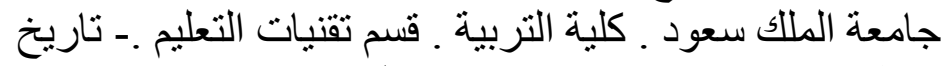
http://www.al -musawi.com/docs/e- الإطلاع(2014/12/18).-- متاح على على learning/01?pdf

$$
\text { (9 ) (1 ) عو اطف ابر اهيم محمد ـ مصدر سابق.ص9. السيد العرينى. مصدر سابق.ص12. }
$$




$$
\begin{aligned}
& \text { (11 ) عو اطف ابر اهيم ـ مصدر سابق. ص ص 7-8. } \\
& \text { (r I ) عو اطف إبر اهيم محمد . مصدر سابق . ص } 17 . \\
& \text { (r, ) المصدر السابق ـ ص } 37 . \\
& \text { ( ع ) ) محمد مسردة . مصدر سابق . ص } 136 .
\end{aligned}
$$

(10 ) محسن السيد العرينى . مصدر سابق. ص ص 68-69. 